DOI: 10.12957/demetra.2015.16054

\title{
O reconhecimento de comidas, saberes e práticas alimentares como patrimônio cultural imaterial
}

\section{The recognition of food, food-related knowledge and practices as intangible cultural heritage}

\author{
Juliana Santilli' \\ 1 Promotora de Justiça do Ministério Público \\ do Distrito Federal. Pesquisadora associada ao \\ programa "Populações locais, agrobiodiversidade \\ e conhecimentos tradicionais", realizado em \\ parceria entre o Institut de Recherche pour le \\ Développement (IRD), e a Universidade Estadual \\ de Campinas (Unicamp). \\ Correspondência / Correspondence \\ Juliana Santilli \\ E-mail: juliana.santilli2014@gmail.com
}

\section{Resumo}

$\mathrm{O}$ artigo analisa algumas iniciativas recentes de patrimonialização de comidas, saberes e práticas alimentares, no âmbito internacional e nacional. Na Unesco, são analisados os processos de reconhecimento, como "patrimônio cultural imaterial", da dieta mediterrânea, da gastronomia tradicional mexicana, da comida gastronômica dos franceses, do Washoku (sistema culinário japonês) e do pão de gengibre da Croácia. Iphan já registrou como bens culturais imateriais: o ofício das baianas de acarajé, a produção tradicional de cajuína no Piauí, o modo artesanal de fazer queijo minas e o sistema agrícola tradicional do Rio NegroAM. Há outras iniciativas em curso, como o ofício das tacacazeiras do Pará. O artigo discute os principais questionamentos em torno de tais iniciativas, e os potenciais avanços que elas podem representar para promover a diversidade alimentar como expressão da diversidade cultural.

Palavras-chave: Comidas. Saberes e Práticas Alimentares. Patrimônio Cultural. Biodiversidade.

\section{Abstract}

The article analyzes some recent initiatives of patrimonialization of food, knowledge and feeding practices at international and national levels. UNESCO analyzes the recognition processes, as "intangible cultural heritage", of the Mediterranean diet, the traditional Mexican cuisine, the gastronomic French food, 
the Washoku (the Japanese culinary system), and Croatian gingerbread. Iphan has recorded as intangible cultural heritage: the office of the Bahian acaraje, the traditional production of cajuina in Piauí; the artisan way of making white cheese in Minas Gerais, and the traditional agricultural system of the Rio Negro, Amazonas state. There are other ongoing initiatives such as the office of the tacacazeiras in Para. The article discusses the main questions around such initiatives, and the potential improvements they can pose in promoting food diversity as an expression of cultural diversity.

Key words: Food. Food-related Knowledge and Practices. Cultural Heritage. Biodiversity.

\section{Introdução}

\section{Comidas, saberes e práticas alimentares, um patrimônio cultural}

O reconhecimento de que a alimentação humana é muito mais do que um fato biológico, mas um ato social e cultural, já está consolidado nos estudos antropológicos. ${ }^{1-6}$ A cultura alimentar tem sido compreendida como "o conjunto de representações, crenças, conhecimentos e práticas herdadas e/ou aprendidas que estão associadas à alimentação e são compartilhadas pelos indivíduos de uma dada cultura ou de um grupo social determinado". ${ }^{3}$

Para Matta, ${ }^{7}$ o patrimônio alimentar, de forma mais ampla, pode ser definido como "um conjunto de elementos materiais e imateriais das culturas alimentares considerados como uma herança compartilhada, ou como um bem comum, por uma coletividade". O patrimônio alimentar envolve componentes materiais - como os alimentos em si, artefatos e utensílios culinários - e imateriais - como práticas, saberes, representações, etc. Não se pode compreender os bens culturais sem considerar os valores e significados neles investidos (sua dimensão imaterial), e não é possível compreender a dinâmica do patrimônio imaterial sem o conhecimento da cultura material que lhe dá suporte. ${ }^{8}$

Os produtos alimentares, bem como os objetos e conhecimentos usados na produção, transformação e consumo de alimentos, têm sido identificados como objetos culturais portadores da história e da identidade de um grupo social. ${ }^{2}$ A alimentação implica representações e imaginários, envolve escolhas, símbolos e classificações, e as diferentes formas de produção e consumo dos alimentos revelam identidades culturais. ${ }^{1}$ 
Em um mundo cada vez mais dominado por um modelo de alimentação industrial e homogêneo, surge, paradoxalmente, um forte movimento de valorização de sistemas alimentares locais e territorializados, portadores de importantes referências culturais que devem ser preservadas. Se os sistemas alimentares diferentes correspondem a sistemas culturais distintos, ${ }^{3}$ os produtos, práticas e saberes alimentares locais se tornaram símbolo de resistências culturais contra a homogeneização. Afinal, os alimentos expressam tradições e práticas culturais das comunidades que os produzem e consomem, e estão inseridos em sistemas sociais e culturais específicos, que atribuem distintos significados ao que se come, como, quando e com quem se come. ${ }^{1}$

É nesse contexto que devemos entender o crescente reconhecimento de comidas, saberes e práticas alimentares como patrimônio cultural, tanto por agências internacionais, como a Organização das Nações Unidas para a Educação, a Ciência e a Cultura (Unesco), como nacionais, como o Instituto do Patrimônio Histórico e Artístico Nacional (Iphan).

\section{A Unesco e o reconhecimento de comidas, pratos típicos e sistemas alimentares como patrimônio cultural imaterial da Humanidade}

No plano internacional, o reconhecimento de sistemas alimentares como patrimônio cultural tem ocorrido principalmente no âmbito da Convenção da Unesco para a Salvaguarda do Patrimônio Cultural Imaterial, aprovada em 2003 mas que entrou em vigor em 2006. Segundo esse documento, patrimônio cultural imaterial são as práticas, representações, expressões, conhecimentos e técnicas -instrumentos, objetos, artefatos e lugares culturais que lhes são associados - que as comunidades, os grupos e, em alguns casos os indivíduos, reconhecem como parte integrante de seu patrimônio cultural. Para a Unesco, o "patrimônio cultural imaterial” se manifesta em particular nos seguintes campos: tradições e expressões orais, incluindo o idioma como veículo do patrimônio cultural imaterial; expressões artísticas; práticas sociais, rituais e atos festivos; conhecimentos e práticas relacionados à natureza e ao universo e técnicas artesanais tradicionais.

Entre os bens culturais imateriais brasileiros reconhecidos pela Unesco, estão a roda de capoeira, o Círio de Nazaré, de Belém e o frevo do carnaval, de Recife. Já foram reconhecidas também as manifestações do Dia dos Mortos, no México, a música Marimba, da Colômbia, e a Huaconada, ritual de dança dos Andes Peruanos, entre outros.

O reconhecimento como patrimônio cultural imaterial implica a obrigação do país de adotar medidas de salvaguarda, que visam garantir a viabilidade do patrimônio cultural imaterial, tais como identificação, documentação, investigação, preservação, proteção, promoção, valorização, transmissão - essencialmente por meio da educação formal e não-formal - e revitalização deste patrimônio em seus diversos aspectos. Além disto, implica o direito de acessar fundos de cooperação e assistência internacionais para salvaguardar o bem reconhecido. 
Mais recentemente, a Unesco tem incluído em sua Lista Representativa do Patrimônio Cultural Imaterial da Humanidade diversas comidas, saberes e práticas alimentares. Vejamos alguns exemplos, para depois fazermos uma análise.

Dieta mediterrânea - o reconhecimento foi inicialmente proposto (e aprovado pela Unesco) em 2010 por Itália, Espanha, Marrocos e Grécia, mas em 2013 foram incluídos também Portugal, Croácia e Chipre. A dieta mediterrânea está associada ao cultivo e consumo de azeite de oliva, frutas e vegetais frescos, frutos do mar, alguns grãos e vinho, bem como às habilidades, conhecimentos, práticas e tradições associados à produção e ao consumo destes alimentos ("da paisagem até a mesa"), e é considerada nutritiva e saudável, bem como responsável pela longevidade das comunidades que a adotam. As práticas de comensalidade e sua importância para o fortalecimento dos laços sociais foram também motivos determinantes para seu reconhecimento. ${ }^{9}$

Gastronomia tradicional mexicana da região de Michoacán - reconhecida em 2010, é definida pela Unesco como um "modelo cultural abrangente, que compreende agricultura, práticas rituais e celebrações (como o Dia dos Mortos), costumes, habilidades e técnicas culinárias tradicionais, e que envolve a participação coletiva em toda a cadeia alimentar: desde o plantio e colheita dos alimentos até seu preparo e consumo. O sistema é baseado no milho, feijão e pimentas, mas inclui outros ingredientes nativos, como uma grande diversidade de tomates, abóboras, abacates, cacau e baunilha. Inclui práticas agrícolas únicas, como os chinampas ("ilhas ou jardins flutuantes", construídos em madeira trançada sobre áreas lacustres, nos quais se realiza o cultivo agrícola) e milpas (cultivo rotativo de milho e outras culturas, especialmente feijão e abóbora, em que após dois anos de cultivo, a terra "descansa" por cerca de oito anos, para que o solo recomponha sua fertilidade); processos de cozimento como a nixtamalização (processo de cozimento e maceração do milho maduro em solução alcalina). Ao contrário da dieta mediterrânea, em que são destacados elementos comuns de um sistema alimentar presente em vários países do Mediterrâneo, a designação mexicana enfocou uma cozinha regional específica (de Michoacán), vista como uma metonímia da cultura alimentar do país como um todo, ${ }^{10}$ apesar da grande diversidade cultural das tradições alimentares mexicanas.

Comida gastronômica dos franceses, ou refeição "à moda francesa" -também reconhecida em 2010, a designação "francesa" enfatiza não uma cozinha particular ou regional, ou mesmo alimentos, pratos ou ingredientes típicos, mas o que é percebido (nos chamados "imaginários culinários"10) como uma forma tradicionalmente francesa de consumir alimentos. É descrita como uma prática social ou costume francês para celebrar momentos importantes como nascimentos, aniversários, casamentos, etc., em que se enfatizam a comensalidade e a reunião de pessoas para comer e beber com prazer e de forma estruturada e ritualizada, incluindo a combinação da comida com o vinho, 
a decoração da mesa e a estruturação da refeição em sequência (com aperitivo, entrada, prato principal, queijo e sobremesa), entre outros elementos.

Arte tradicional de fazer pão de gengibre do norte da Croácia-reconhecida em 2010. Apesar de a receita de pão de gengibre ter ingredientes simples (açúcar, farinha, água, fermento, gengibre e especiarias) e ser bastante difundida em outros países, os croatas argumentam que foram eles que desenvolveram diversas formas de moldar o pão de gengibre e decorá-los com cores vivas e mensagens para casamentos e outras comemorações. Para os croatas, apesar de a tradição de fazer pão de gengibre ser multinacional, foi na Croácia que ela "se tornou uma arte", e um dos símbolos da identidade cultural croata, especialmente em Zagrebe. ${ }^{11}$

Washoku, sistema alimentar e culinário tradicional dos japoneses, principalmente no Ano Novo - reconhecido pela Unesco em 2013. Como explica Kumakura, ${ }^{12}$ um dos autores da proposta japonesa enviada à Unesco, Washoku não é um prato específico, mas todo um sistema que compreende as refeições domésticas diárias (que inclui arroz, sopa, um prato principal e dois ou três acompanhamentos e picles), os alimentos associados a festas e cerimônias (como zoni* $e$ osech $^{* *}$ ) e as especialidades culinárias regionais. Washoku utiliza diversos frutos do mar, produtos agrícolas e plantas silvestres comestíveis, e o respeito à natureza é um dos traços característicos deste sistema alimentar, no qual se privilegiam alimentos locais e sazonais, procurando-se respeitar e realçar seus sabores naturais. Em termos de gosto, Washoku busca destacar o Umami, um dos cinco gostos básicos, junto com doce, azedo, amargo e salgado. Umami é uma palavra de origem japonesa que significa "gosto saboroso e agradável." ${ }^{* * *}$ O pedido de reconhecimento pelo governo japonês foi motivado, por um lado, por sua preocupação com a baixa autossuficiência alimentar do país (muito dependente de importações); por um sentimento nacionalista, já que a cultura alimentar tradicional está muito associada à identidade cultural japonesa; e pelo aumento de doenças cardiovasculares, diabetes e obesidade, associadas ao consumo de comidas ocidentais do tipo fast food, principalmente nas grandes cidades e entre jovens.

* Zoni é uma sopa de vegetais com bolinhos de arroz, tradicionalmente consumida pelos japoneses no Ano Novo, considerada um alimento auspicioso (que traz boa sorte).

** Osechi é uma refeição especial japonesa consumida tradicionalmente no Ano Novo, em caixas especiais chamadas jubako, e cujos pratos possuem significados especiais, como Kombu, uma alga marinha, associada a alegria, o Kazunoko, ovas de arenque que simbolizam prosperidade, o Kuro-mame, soja preta, que simboliza saúde, o Kamaboko, feito de massa ou pasta de peixe curtido (surimi), associado ao Sol Nascente (símbolo do Japão), entre outros.

*** Por muito tempo, os cientistas debateram se o Umami era mesmo um gosto básico, mas hoje ele é amplamente aceito como o quinto gosto básico, e reconhecido como o termo científico para descrever o gosto dos glutamatos e nucleotídeos.O gosto Umami é comum em alimentos que contêm altos níveis de ácido glutâmico, monofosfato de guanosina (GMP) e monofosfato de inosina (IMP), principalmente em peixes, crustáceos, carnes curadas, legumes (por exemplo repolho, espinafre, etc.), cogumelos, tomates maduros, ou chá verde e produtos fermentados e envelhecidos (por exemplo queijos, pastas de camarão, molho de soja, etc.).O Umami possui um gosto residual suave mas duradouro, difícil de descrever. Ele induz a salivação e uma sensação aveludada na língua. Sozinho, o Umami não é saboroso, mas torna agradável uma grande variedade de alimentos. 
Outras comidas reconhecidas pela Unesco foram um prato tradicional e cerimonial da Turquia, o keshkek, feito de trigo e carne (2011); a cultura e tradição do café, também da Turquia (2013); e o kimchi, da Coreia do Sul, picles de vegetais (principalmente rabanete) feitos em conserva durante a celebração tradicional chamada de kimjang, quando se faz e compartilha o kimch (2013).****A Itália apresentou a candidatura da arte tradicional dos mestres pizzaiolos napolitanos, e o Peru apresentou a candidatura da culinária peruana, ambos ainda não reconhecidos pela Unesco.

A designação japonesa seguiu uma tendência semelhante à francesa e à mediterrânea: ao invés de propor o reconhecimento de um alimento específico e de práticas e saberes especificamente relacionados a este alimento (como o pão de gengibre da Croácia, o keshkek e a cultura do café da Turquia), ou relacionado a uma região específica (como Michoacán, no caso da gastronomia mexicana), o governo japonês defendeu a candidatura do Washoku como um sistema alimentar que marca uma identidade nacional, enfatizando valores culturais associados à alimentação, como saúde e bem-estar, que são compartilhados pela sociedade japonesa e transmitidos de geração em geração. ${ }^{10}$

Alguns críticos ${ }^{10}$ consideram que a Unesco tem privilegiado sistemas alimentares já reconhecidos internacionalmente, e que as candidaturas são motivadas sobretudo por interesses comerciais e de promoção do turismo gastronômico. Argumenta-se que as indicações da Unesco teriam se voltado pouco para sistemas alimentares menos conhecidos internacionalmente, mas igualmente importantes do ponto de vista da diversidade biológica e cultural que contêm. Além disto, argumenta-se que não são claros os critérios para a escolha dos sistemas alimentares "dignos" de reconhecimentos como patrimônio cultural, que aspectos dos sistemas alimentares devem ser valorizados, etc.

Para outros analistas, ${ }^{7}$ em um contexto de comercialização da cultura, a patrimonialização permitiu que certos aspectos da culinária fossem selecionados por diferentes grupos sociais para afirmar sua identidade cultural/nacional e suas diferenças em relação a outros grupos, e ao mesmo tempo assegurar um nicho no mercado global das cozinhas étnicas e nacionais e valorizar as atividades humanas que estas envolvem.

Um dos avanços da Convenção da Unesco é justamente a participação das comunidades locais nos processos de reconhecimento e salvaguarda dos bens culturais protegidos. Segundo a convenção, só poderão ser considerados como patrimônio cultural imaterial as expressões e manifestações culturais que gerem um "sentimento de identidade e continuidade" para as comunidades locais, o que representa um novo paradigma.

**** Para mais informações, consultar: www.unesco.org/culture/ich 
As políticas patrimoniais da Unesco sempre suscitaram questionamentos em relação à sua legitimidade social e política: quem seleciona os bens culturais que devem ser preservados? A partir de que valores, em nome de que interesses e de que grupos sociais? Afinal, o papel de selecionar os bens a serem protegidos era atribuído principalmente a técnicos e especialistas, ${ }^{13} \mathrm{e}$ não às comunidades locais. O novo paradigma adotado pela Convenção do Patrimônio Imaterial desloca o foco dos bens em si mesmos para os sujeitos que lhes atribuem sentidos e valores, ou seja, reconhece que o valor dos bens lhes é sempre atribuído por sujeitos particulares e em função de determinados critérios e interesses historicamente situados. ${ }^{13}$

Por outro lado, o conceito de "comunidade local" estabelecido na convenção tem sido criticado por não considerar a complexidade e as conflitualidades que lhe são inerentes. Muitas vezes as comunidades locais não são homogêneas e consensuais, podendo haver conflitos motivados por interesses específicos ou desigualdades de poder dentro das próprias comunidades. ${ }^{14}$ Não é fácil definir quem são as comunidades detentoras dos saberes e práticas que se pretende preservar, sobretudo quando se trata de manifestações culturais compartilhadas por diferentes comunidades ou amplamente difundidas fora de suas regiões de origem. Há também situações em que a própria definição da comunidade detentora pode gerar conflitos e rivalidades entre as comunidades, ou mesmo gerar reivindicações de direitos exclusivistas sobre os bens protegidos, o que contraria a própria noção de bem "comum" a que está associado o reconhecimento de um bem como "patrimônio da humanidade".

No caso da dieta mediterrânea, por exemplo, as práticas alimentares definidas como tal são características principalmente das comunidades de Cilento, na Itália, Chefchaoun, no Marrocos, Soria, na Espanha e Koroni, na Grécia, onde se desenvolveram as pesquisas destinadas a fundamentar a candidatura junto à Unesco. ${ }^{15}$ Tais práticas seriam representativas da chamada dieta mediterrânea. Em face da grande diversidade cultural existente no Mediterrâneo, bem como das especificidades e adaptações locais, a verdadeira representatividade dessas comunidades pode ser questionada. Ademais, Portugal, Croácia e Chipre pediram (e conseguiram) sua inclusão posterior, revelando as dificuldades para delimitação geográfica do sistema alimentar protegido.

Por outro lado, a eleição da gastronomia tradicional de Michoácan como representativa da mexicana também gerou questionamentos, principalmente por parte do Estado de Oaxaca, que tenta obter igual reconhecimento pela Unesco. Oaxaca é um dos estados mexicanos com maior diversidade étnica, em que pelo menos 15 línguas indígenas diferentes são faladas, e que conseguiu se manter relativamente isolado da influência cultural norteamericana, o que se reflete em sua rica e diversificada culinária.

Muitos pratos típicos são associados a Oaxaca, como os chapulines (gafanhotos temperados fritos), tlayudas (grandes tortillas recheadas com feijões, gordura de porco, abacate, queijo e carne), quesillo (queijo de corda) gusanos (larvas encontradas nas plantas de agave, usadas para fazer 
mezcal e tequila, usados como um ingrediente para fazer salsa). Portanto, a eleição da culinária de Michoacán, e não de Oaxaca, para representar o México, não é consensual. ${ }^{16}$

As candidaturas mais amplas - como a da gastronomia francesa e a proposta peruana - podem criar dificuldades para a adoção de medidas de salvaguarda, com educação alimentar, campanhas de conscientização etc. que devem se destinar a comunidades específicas, estabelecidas em áreas geográficas precisas. Entretanto, têm caráter mais inclusivo e integrador ${ }^{7}$ do que as candidaturas de regiões específicas (como das gastronomias de Michoacán e Oxaca).

\section{Proteção jurídica ao patrimônio cultural brasileiro e os instrumentos de salvaguarda dos bens culturais imateriais}

Antes mesmo da entrada em vigor da Convenção da Unesco, em 2006, a Constituição brasileira aprovada em 1988 já consagrava uma nova concepção de patrimônio cultural, mais abrangente e democrática, que engloba não só os bens culturais materiais ou tangíveis, como os bens imateriais ou intangíveis.

Em 2000, a Presidência da República, através do Decreto no 3.551, ${ }^{17}$ instituiu o Registro de Bens Culturais de Natureza Imaterial, criou o Programa Nacional do Patrimônio Imaterial (PNPI) e consolidou o Inventário Nacional de Referências Culturais (INCR), com base no novo conceito constitucional de patrimônio cultural. A Constituição é clara quando estabelece que constituem patrimônio cultural brasileiro os bens de natureza material e imaterial, incluindo, entre eles, as formas de expressão, os modos de criar, fazer e viver e as criações científicas, artísticas e tecnológicas, dos diferentes grupos sociais brasileiros.

Além do tombamento, que se destina especialmente à proteção de bens culturais materiais, como edificações e conjuntos históricos urbanos, a Constituição previu ainda a realização de inventários e registros, instrumentos mais adequados ao reconhecimento e à preservação dos bens culturais imateriais, de natureza processual e dinâmica. Afinal, os bens culturais imateriais - saberes, ofícios, modos de fazer, celebrações e formas de expressão - são constantemente recriados pelas comunidades e grupos em função de sua interação com a natureza e de sua história.18,19

O Decreto no $\mathbf{3 . 5 5 1} / \mathbf{2 0 0 0}^{17}$ rege o processo de reconhecimento de bens culturais como patrimônio imaterial e estabelece a obrigação do Estado de inventariar, documentar, produzir conhecimento e apoiar a dinâmica dos bens culturais imateriais. O registro é um instrumento legal que visa reconhecer e valorizar esses bens, estando dividido nas seguintes categorias:

1) o Livro de Registro dos Saberes, onde são inscritos os conhecimentos e modos de fazer enraizados no cotidiano das comunidades (por exemplo, o ofício das paneleiras de Goiabeiras, no Espírito Santo); 
2) o Livro de Registro das Celebrações, onde são inscritos os rituais e festas que marcam a vivência coletiva do trabalho, da religiosidade, do entretenimento e de outras práticas da vida social (por exemplo, o Círio de Nazaré, em Belém, Pará e a Festa do Divino Espírito Santo, em Pirenópolis, Goiás);

3) o Livro de Registro das Formas de Expressão, onde são inscritas as manifestações literárias, musicais, plásticas, cênicas e lúdicas (por exemplo, arte gráfica Kusiwa dos índios Waiãpi, do Amapá e o Toque dos Sinos, em Minas Gerais);

4) o Livro de Registro dos Lugares, onde são inscritos os mercados, feiras, santuários, praças e demais espaços onde se concentram e reproduzem práticas culturais coletivas (por exemplo, a Cachoeira de Iauaretê, lugar sagrado para os povos indígenas do alto Rio Negro, localizada no distrito de Iauaretê, município de São Gabriel da Cachoeira, no Amazonas, e a Feira de Caruaru, em Pernambuco).

O registro deve contar sempre com o apoio dos grupos sociais envolvidos, mas os bens culturais protegidos não geram necessariamente produtos e serviços com um valor econômico, ainda que tenham forte valor cultural, simbólico, político, social etc. ${ }^{20,21}$

Além da outorga do título de "patrimônio cultural do Brasil”, o registro gera a obrigação dos poderes públicos de promover ações de salvaguarda, a fim de apoiar sua continuidade e as condições sociais e materiais que possibilitam sua existência. O Iphan deve fazer a reavaliação dos bens culturais registrados pelo menos a cada dez anos, a fim de decidir sobre a revalidação (ou não) do título de patrimônio cultural do Brasil. Além do registro, o Programa Nacional do Patrimônio Imaterial adota como instrumentos o Inventário Nacional de Referências Culturais (INRC) e os Planos de Salvaguarda.

O INRC é uma metodologia de pesquisa desenvolvida pelo IPHAN para produzir conhecimentos sobre os domínios da vida social aos quais são atribuídos sentidos e valores e que, portanto, constituem marcos e referências de identidade para determinado grupo social. O INRC se organiza a partir das categorias definidas pelo Decreto n 3.551/2000 - celebrações, ofícios e modos de fazer, formas de expressão e lugares - acrescidas da categoria edificações, dirigida à identificação de bens imóveis, seus usos e as representações sociais associados a eles. O INRC é um instrumento de identificação de bens culturais imateriais $e$ materiais. ${ }^{18,19}$

Os conhecimentos gerados durante os processos de inventário e registro permitem identificar as formas mais adequadas de salvaguarda dos bens culturais imateriais. Para o Iphan, salvaguardar um bem cultural de natureza imaterial é atuar no sentido da melhoria das condições sociais e materiais de transmissão e reprodução que possibilitam sua existência. Os Planos de Salvaguarda visam apoiar a transmissão dos saberes e habilidades relacionados ao bem cultural imaterial, promovê-lo e divulgá-lo e valorizar seus mestres e executantes. As medidas de salvaguarda podem 
ir desde a ajuda financeira a detentores de saberes específicos com vistas a sua transmissão, até a organização comunitária ou a facilitação de acesso a matérias-primas. ${ }^{18}$

Discutiremos alguns bens culturais imateriais já registrados ou em processo de registro pelo Iphan, e outros inventariados através da metodologia do INRC, procurando mostrar como as comidas e as práticas, saberes e fazeres associados aos sistemas alimentares constituem referências culturais fundamentais para os grupos sociais, justificando seu reconhecimento como patrimônio cultural e a adoção de planos e políticas para salvaguardá-los.

Antes, entretanto, merece ser destacado que em reunião realizada em 2005, a Câmara de Patrimônio Imaterial do Iphan entendeu que o instrumento de registro não se destina ao reconhecimento de receitas de comida. Para o Iphan, a comida e seus modos de produção e consumo serão sempre considerados como parte do registro de celebrações, lugares e formas de expressão, ou como parte de sistemas agrícolas ou culinários, nos quais sejam identificados e claramente descritos os conhecimentos, saberes e técnicas implicados nos processos de seleção, apresentação, produção e/ou obtenção de alimentos e seus modos de preparação e consumo, relacionados a grupos e/ou comunidades que lhes atribuem sentido e significado. Assim, seu valor cultural e patrimonial não reside em um prato típico ou em sua receita, mas nas práticas de comensalidade, nos rituais e nos significados que lhes são atribuídos. ${ }^{22}$

Com base em tais fundamentos, o Iphan negou o pedido de registro do sanduíche Bauru, solicitado pela Prefeitura Municipal de Bauru (SP), assim como os pedidos de registro da iguaria Chica Doida (muito apreciada em Goiás, ela é feita com milho verde, linguiça, jiló, queijo e pimenta), do pastel de angu (Itabirito-MG) e do modo de fazer polenta dos descendentes de imigrantes italianos do Vale do Itajaí-SC, embora tenha recomendado a realização de pesquisas mais amplas sobre a culinária e a gastronomia criadas em torno da cultura do milho. Passamos a seguir para os bens já registrados e/ou inventariados pelo Iphan.

\section{Produção tradicional e práticas socioculturais associadas à cajuína no Piauí}

Seu registro no Livro do Registro de Saberes foi realizado em 2014. O cajueiro é uma planta originária do Nordeste do Brasil. Do caju se faz suco, doce, mel, licores e sorvetes, entre outros produtos. A cajuína já foi descrita como "a champagne do Piauí", mas é uma bebida não alcóolica, feita a partir do suco do caju separado do seu tanino, por meio da adição de um agente precipitador (originalmente, a resina do cajueiro, durante muitas décadas a cola de sapateiro e atualmente, a gelatina em pó), coado várias vezes em redes ou funis de pano. Esse processo de separação do tanino do suco recebe o nome de clarificação, e o suco clarificado é então cozido em banho maria em garrafas de vidro até que seus açúcares sejam caramelizados, tornando a bebida amarelada e permitindo que possa ser armazenada por períodos de até dois anos. ${ }^{23}$ 
Segundo o Iphan, a cajuína não é um vinho de caju, e também não é um refresco gaseificado, ou apenas um suco natural. A cajuína é o resultado da eliminação do sabor amargo e adstringente do suco do caju. O Iphan chegou a considerar a possibilidade de que a cajuína fosse incluída em um registro mais amplo dos saberes e fazeres relacionados ao complexo cultural do caju. Entretanto, "não foi identificada na pesquisa, por parte da população piauiense, a mesma relação identitária com os outros produtos oriundos do caju, apesar da extração da castanha ser uma forte fonte de renda por sua cotação no mercado nacional e internacional". ${ }^{23}$

A cajuína está fortemente vinculada à identidade piauiense. Decantada em prosa e versos, a cajuína tornou-se uma bebida obrigatória para todos que querem conhecer os principais aspectos da cultura piauiense, tendo Caetano Veloso a incluído em uma de suas canções: "A cajuína cristalina em Teresina". Mesmo sendo uma bebida, ela assume o simbolismo de alimento, sendo inscrita na mesma tradição dos doces, bolos, biscoitos e outros saberes gastronômicos cultivados no Nordeste. ${ }^{23}$

O pedido de registro do modo tradicional de fazer cajuína no Piauí foi apresentado ao Iphan pela Cooperativa de Produtores de Cajuína do Piauí (CAJUESPI). Ao fundamentar o pedido de registro, a cooperativa destacou a importância de assegurar a participação da pequena agricultura familiar na produção da cajuína no Piauí, em face da preocupação de que a produção industrial e em larga escala da cajuína impactasse negativamente o modo artesanal de sua produção, e a sua vinculação à identidade cultural piauiense. Tal ameaça se tornava mais concreta em face da notícia de que uma grande empresa multinacional (Coca-Cola) pretendia lançar um refrigerante com o nome "Crush Cajuína". Afinal, o modo tradicional de fazer cajuína já havia sido declarado, através de decreto (n⿳0 13.068/2008) do governador do Piauí, como "de relevante interesse cultural". Devido à forte reação da sociedade piauiense, a Coca-Cola recuou e trocou o nome do refrigerante para "Crush Caju", respondendo, parcialmente, aos protestos dos piauienses.

Em face de tal ameaça, o registro da produção tradicional e das práticas socioculturais associadas à cajuína tornou-se um instrumento importante para o fortalecimento das condições tradicionais de produção da cajuína, e de conservação da biodiversidade local e das práticas culturais associadas.

\section{Registro do sistema agrícola tradicional do Rio Negro-AM}

A Associação das Comunidades Indígenas do Médio Rio Negro (ACIMRN) solicitou ao Iphan o registro do sistema agrícola dessa região como patrimônio cultural imaterial no Livro de Registro dos Saberes em 2007, e este foi realizado pelo Iphan em 2010. Segundo Emperaire, Velthem \& Oliveira, ${ }^{24}$ o sistema agrícola tradicional do Rio Negro é um conjunto estruturado, formado por elementos interdependentes: as plantas cultivadas, os espaços, as redes sociais, a cultura material, os sistemas alimentares, os saberes, as normas e os direitos. Esse sistema está ancorado no cultivo da mandioca brava (manihot esculenta) e apresenta como base social os mais de 22 povos indígenas, 
representantes das famílias linguísticas Tukano Oriental, Aruak e Maku, localizados ao longo do rio Negro, em um território que abrange os municípios de Barcelos, Santa Isabel do Rio Negro e São Gabriel da Cachoeira, no estado do Amazonas.

Segundo as autoras, ${ }^{24}$ no contexto do Rio Negro, o sistema agrícola pode ser entendido como saberes, mitos e relatos, práticas, produtos, técnicas, artefatos e outras manifestações associadas que envolvem os espaços manejados e as plantas cultivadas, as formas de transformação dos produtos agrícolas e sistemas alimentares locais. A noção de sistema vincula o bem cultural a um conjunto mais complexo de relações e abre a perspectiva de registro (pelo Iphan) de elementos mais vastos do patrimônio cultural brasileiro, como os sistemas agrícolas, entre os quais o do Rio Negro, que se caracterizam por um conjunto de elementos interdependentes e não por um único objeto ou bem específico. ${ }^{24}$

Trata-se de um sistema agrícola que detém rica agrobiodiversidade. Além da diversidade associada à mandioca, identificou-se alta diversidade de pimentas, abacaxis, inhames e bananas, o que confirma a importância regional do Rio Negro em termos de conservação da diversidade agrícola. Emperaire, Carneiro da Cunha \& Tozzi ${ }^{25}$ destacam que as formas de praticar a agricultura, cuidar das plantas, transformar os produtos da roça e produzir seus alimentos constituem um referencial cultural compartilhado entre os povos do Médio e Alto Rio Negro. Para essas autoras, o pedido de registro do sistema agrícola do Rio Negro como patrimônio cultural imaterial é um exemplo concreto de como os instrumentos e as políticas de salvaguarda do patrimônio cultural podem ser utilizados a favor da agrobiodiversidade, diversidade cultural e sistemas agrícolas locais.

\section{O Inventário Cultural de Quilombos do Vale do Ribeira e o pedido de registro do sistema agrícola do Vale do Ribeira (SP e PR)}

Este inventário identificou 180 bens culturais imateriais relacionados ao modo de vida de 16 comunidades quilombolas que vivem no Vale do Ribeira, classificados como celebrações, formas de expressão, ofícios e modos de fazer, lugares e edificações. Ele foi realizado pelo Instituto Socioambiental (organização da sociedade civil) com a participação das comunidades quilombolas em todas as fases do levantamento das referências culturais. ${ }^{26} \mathrm{O}$ inventário identificou o sistema agrícola quilombola como a base de sustentação de diversas expressões culturais, e tramita no IPHAN desde 2013 o pedido para que seja reconhecido como patrimônio cultural imaterial e inscrito no Livro de Registro de Saberes.

Os quilombolas empregam o sistema de corte e queima, conhecido como coivara, e fazem um rodízio das áreas de plantio, deixando-as em pousio por alguns anos até voltarem a ser produtivas. Pasinato, Andrade \& Wiens ${ }^{27}$ explicam que as roças não são importantes apenas para a segurança alimentar das comunidades quilombolas e para a biodiversidade da Mata Atlântica. 
O modo de fazer roça aparece como bem cultural associado a diversos domínios da vida social. A produção alimentar está relacionada a um conjunto de saberes e práticas ancorados em valores e relações familiares e comunitárias. Este conjunto é a base da organização social e cultural quilombola no qual a roça assume posição central e estruturante. Destacam-se bens culturais como: modo de fazer roça, processamento dos alimentos (arroz, milho, cana, mandioca), ofício de artesão e modo de fazer casa de pau a pique.

Pasinato, Andrade \& Wiens ${ }^{27}$ destacam que há uma série de fatores ameaçando a sobrevivência das roças quilombolas, dentre eles as restrições ambientais ao corte de vegetação nativa, as dificuldades de manter as sementes crioulas, as restrições de espaço territorial por conta da invasão de terceiros nos territórios quilombolas e a falta de mão de obra, pela saída dos jovens do campo para a cidade em busca de trabalho e renda. O reconhecimento do sistema agrícola quilombola como patrimônio cultural imaterial se insere numa estratégia de valorização de práticas e saberes tradicionais detidos pelos quilombolas.

Registro do modo de produção artesanal dos queijos de Minas Gerais e o pedido de registro do modo de fazer queijo artesanal serrano de Santa Catarina e Rio Grande do Sul

Inscrito pelo Iphan no Livro de Registro de Saberes em 2008, o modo de produção artesanal de queijo a partir do leite cru é um traço marcante da identidade cultural das regiões serranas de Minas Gerais (Serro e Serras da Canastra e do Salitre/Alto Paranaíba). Cada região tem um modo de fazer próprio, expresso na forma de manipulação do leite e no tempo de maturação (cura), mas constituem aspectos comuns o uso de leite cru e a adição do "pingo", um fermento láctico natural recolhido a partir do soro que drena do próprio queijo.

Em 2002, o queijo do Serro foi reconhecido como patrimônio cultural de Minas Gerais, e a Lei Estadual no 14.185/2002 (alterada pela Lei Estadual no 19.492/2011) passou a regular o processo de produção do queijo artesanal, permitindo a comercialização de queijo artesanal feito a partir do leite cru no Estado de Minas Gerais. Em dezembro de 2012, foi sancionada, pelo governador de Minas Gerais, uma nova Lei (n- 20.549), que visa criar condições favoráveis para a regularização sanitária dos produtores de queijo. Entre outras novidades, ela atende a antigas reivindicações de produtores, comerciantes e consumidores como a comercialização do queijo meia cura (produto que passou há poucos dias pelo dessoramento).

Outras novidades da lei são: a comercialização através de Serviços de Inspeção Municipal (SIM); a criação de um fundo para indenizar produtores que tenham animais sacrificados por brucelose ou tuberculose; e ainda, o cadastro dos queijeiros (negociantes que transportam o produto da fazenda até os centros urbanos). Entretanto, a legislação federal continuou a impedir 
os produtores de queijo artesanal feito a partir do leite cru a comercializar tal produto fora dos limites do Estado de Minas Gerais, em virtude principalmente da exigência de tempo mínimo de maturação dos queijos de 60 dias, o que contraria o modo de produção tradicional. ${ }^{28}$

Para solucionar a questão, o Ministério da Agricultura (MAPA) editou inicialmente a Instrução Normativa n⿳0 57/2011, e posteriormente a Instrução Normativa nº 30/2013, que passaram a permitir que os queijos artesanais tradicionalmente elaborados a partir de leite cru sejam maturados por um período inferior a 60 dias, quando estudos técnico-científicos comprovarem que a redução do período de maturação não compromete a qualidade e a inocuidade do produto. A IN no 30/2013 passou a estabelecer que a definição do novo período de maturação dos queijos artesanais seria realizada após a avaliação dos estudos pelo órgão estadual e/ou municipal de inspeção industrial e sanitária reconhecidos pelo Sistema Brasileiro de Inspeção de Produtos de Origem Animal (SISBI/POA). Segundo Lima, ${ }^{28}$ foram estabelecidos os períodos de 17 dias de maturação para o queijo Serro e de 22 dias para o queijo Canastra.

Tramita também no Iphan o pedido de registro do modo de fazer queijo artesanal serrano de Santa Catarina e Rio Grande do Sul, formulado pela Associação dos Produtores de Queijo e Derivados do Leite dos Campos de Cima da Serra (Aprocampos-RS) e pela Associação de Produtores Rurais de Capão Alto-SC. Segundo o referido pedido de registro, o queijo artesanal serrano é fabricado com leite bovino, em pequena escala, exclusivamente em estabelecimentos rurais dos campos de altitude da região serrana de SC e dos Campos de Cima da Serra do RS. Sua produção é realizada principalmente por pecuaristas familiares, e constitui sua principal fonte de renda. O modo de fazer queijo serrano é uma prática profundamente enraizada no cotidiano das famílias produtoras.

Em interessante artigo sobre a produção de queijos artesanais brasileiros, em que enfocam sobretudo o queijo de coalho caseiro do sertão sergipano e o queijo serrano, ${ }^{29}$ Fabiana Cruz e Sonia Menezes destacam que destacam que as famílias produtoras de queijos artesanais detêm aprendizados e técnicas de produção queijeira adquiridas e compartilhadas por gerações, e que tais alimentos são parte de modos de vida que conformam cultura e tradição de comunidades rurais e da população urbana, que procura no consumo desses queijos alimentar o corpo e fortalecer sua identidade.

\section{Inventário Nacional de Referências Culturais (INRC) da Produção de Doces Tradicionais de Pelotas (RS) e o pedido de registro.}

Este INRC foi realizado entre os anos de 2006 e 2008, pelo Laboratório de Ensino e Pesquisa em Antropologia e Arqueologia da Universidade Federal de Pelotas. Em 2009, a Câmara de Dirigentes 
Lojistas de Pelotas, com o apoio da Cooperativa das Doceiras de Pelotas, encaminhou ao Iphan o pedido de registro da "produção de doces tradicionais pelotenses". Entretanto, o Iphan ${ }^{30}$ entendeu que o objeto do registro deveria ser a "região doceira de Pelotas e Pelotas antiga", a ser inscrita no Livro de Registro dos Lugares, e não no Livro de Registro de Saberes, como solicitado inicialmente.

Segundo o Iphan, ${ }^{30}$ o município de Pelotas e demais municípios adjacentes são um ponto de convergência que agrega elementos culturais, históricos, demográficos, geográficos, étnicos, tecnológicos e econômicos que, em conjunto, desenvolveram uma personalidade específica para a atividade doceira ali realizada. Para o Iphan, ${ }^{30}$ essa região doceira deve ser entendida como "o espaço onde se concentram e se reproduzem práticas culturais coletivas relacionadas à atividade doceira e que se tornaram referências culturais para grupos sociais". O INRC identificou os grupos sociais envolvidos com a produção doceira e comprovou saberes e fazeres associados com o processo de apropriação e transformação de recursos naturais e práticas culturais. Da mesma forma, o INRC indicou a produção e o consumo de doces em espaços de sociabilidade, como celebrações, e também enquanto prática coletiva enraizada no cotidiano de grupos sociais. Os bens inventariados foram os doces de Pelotas, subdivididos em doces finos (ou de bandeja, como o quindim, olho de sogra, pastel de Santa Clara, camafeu etc.) e doces coloniais (ou de frutas, como compota de pêssego, passa de pêssego, figo cristalizado, marmelada branca, origone ${ }^{* * * * *}$ etc.). ${ }^{30}$

O INRC foi muito além da mera caracterização de receitas e quitutes, e analisou a transmissão de saberes, produção, circulação e consumo dos doces, abarcando complexa dinâmica social. O INRC estabelece, ainda, uma distinção entre a área urbana de Pelotas, onde se concentra a produção de doces finos, em sua maioria de tradição portuguesa, e a área rural, onde houve grande fluxo de imigrantes da França, Itália, Alemanha, e outros países europeus, e se produzem principalmente os doces de frutas. Indica, assim, um cruzamento entre a cartografia cultural e étnica e a geografia do doce. ${ }^{30}$

\section{Pedido de registro do ofício das tacacazeiras}

Este pedido de registro no Livro de Saberes se baseou principalmente nas informações contidas no Inventário Nacional de Referências Culturais do Tacacá em Belém ${ }^{* * * * * *}$. Segundo Pinto, ${ }^{31} \mathrm{o}$ Centro Nacional de Folclore e Cultura Popular (CNFCP) elaborou o projeto "Implantação de Inventários: Celebrações e Saberes da Cultura Popular", abrangendo diferentes campos temáticos, entre os quais os modos de fazer relacionados aos sistemas culinários na Bahia e no Pará.

\footnotetext{
***** Origone é um doce feito de tiras de pêssego desidratadas ao sol.

****** O inventário do tacacá é um desdobramento do inventário sobre os modos de fazer farinha de mandioca, realizado também pelo Centro Nacional de Folclore e Cultura Popular (CNFCP).
} 
No caso do Pará, decidiu-se fazer o inventário da mandioca, principal produto usado na culinária local, que desempenha importante papel na construção de uma identidade regional e apresenta-se como relevante referência cultural. A mandioca e a farinha, seu principal derivado, são usadas por todas as camadas da população e estão presentes tanto nos pratos cotidianos mais simples quanto em outros mais finos e elaborados. É, porém, na região amazônica, particularmente no Pará, que os múltiplos e variados aspectos que envolvem o seu cultivo, transformação em alimento e diversos usos culinários lhe conferem considerável importância histórica, econômica e social.

Segundo Pinto, ${ }^{31,32}$ o modo como a farinha é utilizada no Pará imprime-lhe singularidades uma vez que, além ser a base da alimentação da população mais pobre, é também componente básico de vários pratos de sua cozinha típica, fazendo com que se constitua em importante símbolo de identidade regional. Referências ao pato no tucupi, maniçoba ${ }^{* * * * * *}$ e tacacá, conduzem imediatamente a uma associação com o Pará, em particular com a cidade de Belém. Destaca, ${ }^{31,32}$ entretanto, que embora muitos pratos à base de farinha de mandioca se apresentem como referência cultural, o tacacá merece destaque devido ao processo ritualizado de sua preparação e consumo.

Feito com goma de tapioca e tucupi, subprodutos da mandioca, o tacacá é servido em cuias, utensílio típico do artesanato paraense, e tomado geralmente ao final da tarde, nas esquinas das principais ruas de Belém. As tacacazeiras, com suas barracas, fazem parte da paisagem das ruas de Belém. ${ }^{31-33}$ Para servir o tacacá, é utilizada necessariamente uma cuia, cuja produção é uma atividade associada à da tacacazeira. O tacacá só pode ser servido e saboreado na cuia; ele não é comido nem bebido, mas tomado com o auxílio de um palitinho para pinçar o camarão e o jambu. Os modos de fazer cuias no Baixo Amazonas também foram registrados como bem cultural imaterial.

\section{Registro do ofício das baianas de acarajé}

Realizado em 2004, no Livro de Registro dos Saberes, o pedido de registro foi formulado pela Associação das Baianas de Acarajé, Mingau, Receptivos e Similares do Estado da Bahia, pelo Centro de Estudos Afro-Orientais e pelo Terreiro Ilê Axé Opô Afonjá. Foram realizados três Inventários Nacionais de Referências Culturais relacionados a este bem cultural: do Ofício das Baianas de Acarajé, do Acarajé em Salvador e do Tabuleiro das Baianas em Salvador. O INRC do Ofício das Baianas de Acarajé incluiu a Feira de São Joaquim, um mercado onde é possível encontrar todos os produtos característicos da Bahia e que se apresenta também como um lugar mediador entre a produção e o consumo dos principais ingredientes necessários à preparação tanto das comidas cotidianas quanto das que compõem os tabuleiros da baiana.

*******A maniçoba é preparada com as folhas da mandioca moídas e cozidas, acrescidas de carne de porco, carne bovina e outros ingredientes defumados e salgados. 
O ofício das baianas é uma prática tradicional de produção e venda, em tabuleiro, das chamadas “comidas de baiana”, ligadas ao culto dos orixás, como o acarajé. Este é um bolinho de feijão fradinho, cebola e sal, frito em azeite de dendê. É uma iguaria de origem africana, vinda com os escravos durante a colonização do Brasil. ${ }^{34} \mathrm{O}$ acarajé tem sentido religioso: é comida de santo nos terreiros de candomblé, ofertada aos orixás, principalmente a Xangô e sua mulher, a rainha Oiá (Iansã), deusa guerreira, orixá dos ventos e tempestades. ${ }^{35}$

As baianas de acarajé misturam temperos, como pimenta da costa e outras pimentas, com azeite de dendê, quiabo, feijões, camarão seco e gengibre, para fazer iguarias como acarajé, abará,"* acaçá, ${ }^{* * * * * * * * *}$ bolinho de estudante, ${ }^{* * * * * * * *}$ cocadas, bolos, etc. As baianas estabelecem elos entre os terreiros de candomblé e os espaços públicos da cidade, mantendo viva uma tradição ancestral, importante componente de um sistema culinário que, além de alimentar e satisfazer o paladar, articula diferentes dimensões da vida social: liga os homens aos deuses, o sagrado ao profano, a tradição à modernidade. ${ }^{34}$

O feijão, que é a base do acarajé e de outras iguarias dos tabuleiros das baianas, é também a base da alimentação brasileira, ocupando posição privilegiada em nossos sistemas culinários, e importante papel na construção das identidades regionais, tendo em vista a diversidade de variedades domesticadas e os usos singulares em cada região do país, seja no consumo cotidiano ou ritualizado. Segundo a Empresa Baiana de Desenvolvimento Agrícola (apud Iphan $^{34}$ ), o feijão fradinho é apenas a denominação de uma das muitas variedades do feijão vigna, entre as quais estão o massaca, o boca-preta e o caupi. Percebe-se a apropriação, levada para o espaço do cotidiano e do consumo geral, da influência africana no uso de alimentos, como, por exemplo, o feijão na preparação do acarajé. ${ }^{34}$.

Conforme destacam Bitter \& Bitar, ${ }^{36}$ o registro do ofício das baianas de acarajé foi uma forma de valorização profissional destas, que pretendiam se diferenciar das cozinheiras, que operam dentro de uma cozinha doméstica, enquanto as baianas estão ligadas aos espaços públicos das cidades. Elas também pretendiam se diferenciar de outros ambulantes que vendem alimentos nas ruas de Salvador. Uma das motivações para o pedido de registro foi também a relação conflituosa entre as baianas de acarajé e os evangélicos com seu "acarajé de Jesus". Para as baianas, os evangélicos estariam descaracterizando o acarajé ao associá-lo a Jesus e à Igreja Evangélica, em contraposição ao candomblé. O registro como bem imaterial se configurou como uma demarcação de fronteira

******** O abará é um bolinho de feijão-fradinho moído, embrulhado em folha de bananeira. Ele também é uma comida ritual do candomblé. É feito com a mesma massa que o acarajé, mas o abará é cozido, enquanto o acarajé é frito.

******** O acaçá é feito de uma pasta de milho branco ralado ou moído, envolvida, ainda quente, em folhas de bananeiras.

******** O bolinho de estudante é feito de tapioca granulada, coco ralado e depois de frito é misturado no açúcar e canela. 
entre as baianas e os “outros”: os ambulantes e os evangélicos. ${ }^{* * * * * * * *}$ Além disso, as baianas também sofriam (e sofrem) com ações fiscalizatórias dos órgãos sanitários, e o registro tem sido usado como instrumento de defesa e legitimação de seu ofício perante os próprios órgãos públicos, que tendem a adotar políticas desarticuladas e conflitivas. ${ }^{36}$

Outros registros e pedidos de registro relacionados com sistemas alimentares são: 1) o ofício das paneleiras de Goiabeiras-ES, registrado como bem cultural imaterial no Livro de Registro dos Saberes em 2002. A panela de barro de Goiabeiras constitui suporte indispensável para o preparo da típica moqueca capixaba; e 2) o modo de fazer cuias no Baixo Amazonas, registrado em junho de 2015 no Livro de Registro dos Saberes.

\section{Considerações finais}

A diversidade cultural e a criatividade humana se expressam nas mais diferentes formas de utilização de recursos naturais e de interação do homem com o meio em que vive. Os sistemas alimentares mantêm estreita relação com a cultura, entendida como memória e identidade.

As políticas de salvaguarda dos bens culturais imateriais dependem, entretanto, de melhor articulação com as demais políticas de desenvolvimento econômico e social, para que incluam e valorizem a bio e a sociodiversidade brasileira.

Grande parte das dificuldades enfrentadas pelos detentores de conhecimentos tradicionais está associada à atuação de outros órgãos públicos, que desenvolvem políticas e ações contraditórias com a preservação cultural. Vejamos alguns exemplos.

O modo tradicional de fazer cajuína está ameaçado não só pela iniciativa da Coca-Cola de fazer um refrigerante com o nome "Crush Cajuína”, mas também pela iniciativa do Sebrae de promover a padronização da bebida, a fim de atender aos requisitos necessários ao registro de uma indicação geográfica. A fim de transformar a produção da cajuína em uma indústria de grande porte, capaz de atrair investimentos externos, o Sebrae passou a concentrar seus esforços na padronização da bebida, para que a cajuína passe a ter sempre a mesma cor, teor de açúcar e sabor, o que contraria as práticas locais, que valorizam a diversidade. Além disso, a produção da cajuína a partir do caju clonado acarreta o risco de que cajuais nativos sejam preteridos em favor dos cajuais clonados (geneticamente melhorados), impactando a biodiversidade local.

\footnotetext{
******** O Decreto Municipal no 12.175/1998, do prefeito de Salvador, dispõe sobre a localização e funcionamento do comércio informal exercido pelas baianas de acarajé e de mingau em logradouros públicos. Estabelece que as baianas de acarajé, no exercício de suas atividades em logradouro público, utilizarão vestimenta típica de acordo com a tradição da culinária afro-brasileira. A Lei Federal nº 12.206/2010 estabeleceu o Dia Nacional da Baiana de Acarajé (dia 25 de novembro).
} 
Os produtores de queijo minas artesanal também têm enfrentado uma séria de dificuldades para comercializar o seu produto tradicional, feito a partir de leite cru, fora dos limites do Estado de Minas Gerais. Os principais empecilhos são impostos pela legislação sanitária federal, que obriga a adoção de prazos de maturação, equipamentos e inovações (como a substituição das bancas de madeira por ardósia) que alteram significativamente os modos de produção do queijo, e consequentemente, sua consistência e sabor.

Já as tacacazeiras esperam que o reconhecimento de seu ofício como patrimônio cultural imaterial promova uma melhoria das suas condições de trabalho, pois enfrentam dificuldades para conseguir as autorizações oficiais para se estabelecerem em seus pontos. E ainda, as tacacazeiras sofrem com as restrições impostas pela legislação sanitária, especialmente pela Instrução Normativa no 01/2008, da Agência de Defesa Agropecuária do Pará. ${ }^{36}$

Esta Instrução Normativa estabelece a obrigatoriedade de que todos os estabelecimentos produtores de tucupi obedeçam a determinado "padrão de identidade e qualidade do tucupi", incompatível com as práticas artesanais utilizadas pelas tacacazeiras, que consideram que a referida regulamentação técnica é uma intervenção invasiva no seu ofício. ${ }^{37}$ As medidas para salvaguardar este bem deverão incluir articulações com o referido órgão de defesa agropecuária, para que este reconheça a importância de se preservar as práticas tradicionais das tacacazeiras, e reveja sua legislação.

O que ocorre com o tucupi e as tacacazeiras é paradigmático das dificuldades enfrentadas por muitos outros produtos locais e tradicionais, que não conseguem preencher os requisitos de uma legislação desenvolvida para uma produção industrial e de larga escala de alimentos. As normas sanitárias tendem a promover excessiva homogeneização e industrialização dos produtos, em detrimento de sua identidade e tipicidade. As normas sanitárias devem procurar um equilíbrio entre a saúde e segurança dos alimentos e a valorização de práticas locais e tradicionais relevantes à biodiversidade e à diversidade sociocultural.

Além disso, é fundamental que tais políticas públicas promovam a inclusão social e a melhoria das condições de vida de produtores e detentores do patrimônio cultural imaterial. O desenvolvimento social e econômico deve ser integrado à conservação do meio ambiente e à inclusão social e produtiva de povos e comunidades tradicionais e agricultores familiares, com respeito a suas especificidades culturais e étnicas. Afinal, não há desenvolvimento efetivo e verdadeiro sem a incorporação das referências culturais dos grupos sociais envolvidos. 


\section{Referências}

1. Menasche R, Alvarez M, Collaço J. Alimentação e cultura em suas múltiplas dimensões. In: Menasche R, Alvarez M, Collaço J, organizadores. Dimensões socioculturais da alimentação: diálogos latinoamericanos. Porto Alegre: UFRGS; 2012. p. 7-28.

2. Poulain JP. Sociologias da alimentação: os comedores e o espaço social slimentar. 2. ed. Florianópolis: UFSC; 2013.

3. Contreras J, Gracia M. Alimentação, sociedade e cultura. Rio de Janeiro: Fiocruz; 2011.

4. Katz E. Alimentação indígena na América Latina: comida invisível, comida de pobres ou patrimônio culinário? In: 26a Reunião Brasileira de Antropologia; 1-4 jun. 2008; Porto Seguro, BA. Disponível em URL: http://www.abant.org.br/conteudo/ANAIS/CD_Virtual_26_RBA/mesas_redondas/ trabalhos/MR\%2013/esther\%20katz.pdf

5. Fischler C. El (h)omnívoro: el gusto, la cocina y el cuerpo. Barcelona: Anagrama; 1995.

6. Lévi-Strauss C. O cru e o cozido. São Paulo: Brasiliense; 1991.

7. Matta R. El patrimonio culinario peruano ante Unesco: alguns reflexiones de gastro-política, desigualdades. Berlin: desiguALdades.net Research Network on Interdependent Inequalities in Latin America; 2012. 45 p. Working Paper Series, 28.

8. Sant'anna M, organizador. O registro do patrimônio imaterial: dossiê final da Comissão e do Grupo de Trabalho sobre Patrimônio Imaterial. 5a. ed. Brasília: IPHAN; 2012. (Edições do Patrimônio).

9. International Centre for Advanced Mediterranean Agronomic Studies. Mediterra 2012: the mediterranean diet for sustainable regional development. Paris: Presses de Sciences Po; 2012.

10. Brulotte RL, Di Giovine M, editores. Edible identities: food and foodways as cultural heritage. London: Ashgate Publishing; 2014.

11. Unesco. Gingerbread craft from Northern Croatia: inscribed in 2010 on the representative list of the intangible cultural heritage of humanity. [acesso em: 30 jun. 2015]. Disponível em: http://www. unesco.org/culture/ich/RL/00356

12. Kumakura I. Washoku joins Unesco's intangible cultural heritage list. Food Culture 2014; (24):35. [acesso em: 30 mar. 2015]. Disponível em: http://www.kikkoman.co.jp/kiifc/foodculture/ pdf_24/e_003_005.pdf

13. Fonseca MCL. O Patrimônio em processo: trajetória da política federal de preservação no Brasil. 2. ed. Rio de Janeiro: UFRJ, IPHAN; 2005.

14. Bortolotto C, directeur. Le patrimoine culturel immatériel: enjeux d'une nouvelle catégorie. Paris: Maison des Sciences de l’Homme; 2011.

15. Petrillo PL. La dimensione culturale del patrimonio agro-alimentare Italiano in ambito Unesco: Strumenti e Procedure. In: Scovazzi T, Ubertazzi B, Zagato L, curatori. Il patrimonio culturale intangibile nelle sue diverse dimensioni. Milano: Giuffré; 2012. p. 211-31. 
16. Brulotte RL, Starkman A. Caldo de piedra and claiming pre-hispanic cuisine as cultural heritage. In: Brulotte RL, Di Giovine M, editores. Edible identities: food and foodways as cultural heritage. London: Ashgate Publishing; 2014. p. 109-23.

17. Brasil. Decreto no. 3.551 de 04 de agosto de 2000. Institui o Registro de Bens Culturais de Natureza Imaterial que constituem patrimônio cultural brasileiro, cria o Programa Nacional do Patrimônio Imaterial e dá outras providências. Diário Oficial da União 7 ago. 2000; Seção 1: 2.

18. Brasil. Instituto do Patrimônio Histórico e Artístico Nacional. Os sambas, as rodas, os bumbas, os meus e os bois: princípios, ações e resultados da política de salvaguarda do patrimônio cultural imaterial no Brasil, 2003 - 2010. 2. ed. Brasília: IPHAN; 2010.

19. Brasil. Instituto do Patrimônio Histórico e Artístico Nacional. Patrimônio imaterial: fortalecendo o sistema nacional. Brasília: IPHAN; 2014.

20. Santilli J. Agrobiodiversidade e direitos dos agricultores. São Paulo: Peirópolis; 2009.

21. Santilli J. Socioambientalismo e novos direitos: proteção jurídica à diversidade biológica e cultural. São Paulo: Peirópolis, IEB, ISA; 2005.

22. Brasil. Instituto do Patrimônio Histórico e Artístico Nacional. Memória da $5^{\text {a }}$. Reunião da Câmara do Patrimônio Imaterial. Brasília: IPHAN; 2005.

23. Brasil. Instituto do Patrimônio Histórico e Artístico Nacional. Processo no 01450.014375/2008/87, que trata do registro da produção tradicional e das práticas socioculturais associadas à cajuína no Piauí. Parecer no 28/2014, da técnica Ellen Krohn, e Parecer no 104/2014, do procurador federal Antonio Fernando Alves Leal Neri. Brasília: IPHAN; 2014.

24. Emperaire L, Velthem L, Oliveira AG. Patrimônio cultural imaterial e sistema agrícola: o manejo da diversidade agrícola no Médio Rio Negro (AM). In: $26^{a}$ Reunião Brasileira de Antropologia; 1-4 jun. 2008; Porto Seguro (BA). Disponível em: http://uc.socioambiental.org/sites/uc.socioambiental. org/files/Laure_Emperaire_0.pdf.

25. Emperaire L, Carneiro da Cunha M, Tozzi D. Manivas e papas: três experiências de patrimonialização da agrobiodiversidade. In: Bustamante P, Barbieri RL, Santilli J, organizadores. Agrobiodiversidade. Brasília: Embrapa; 2015. (Coleção Transição Agroecológica). No prelo.

26. Andrade AM, Tatto N, editores. Inventário cultural de quilombos do vale do Ribeira. São Paulo: Instituto Socioambiental; 2013.

27. Pasinato R, Andrade AMC, Wiens I. Quilombos do Ribeira e as roças da agrobiodiversidade. In: Bustamante P, Barbieri RL, Santilli J, organizadores. Agrobiodiversidade. Brasília: Embrapa; 2015. (Coleção Transição Agroecológica). No prelo.

28. Lima RS. Queijo minas artesanal: impasses e trajetórias vivenciadas pelos produtores rurais para manter uma cultura tradicional. In: 29a Reunião Brasileira de Antropologia; 03-06 ago. 2014; Natal (RN). Disponível em: http://www.29rba.abant.org.br/resources/anais/1/1401979833_ ARQUIVO_TRAJETORIASVIVENCIADASPELOSPRODUTORESRURAISPARAMANTER UMACULTURATRADICIONAL.pdf 
29. Cruz FT, Menezes SS. Diversidade e alimentos tradicionais: modos de vida e uso de recursos naturais sob a ótica da produção e do processamento de queijos artesanais brasileiros. In: Bustamante P, Barbieri RL, Santilli J, organizadores. Agrobiodiversidade. Brasília: Embrapa; 2015. (Coleção Transição Agroecológica). No prelo.

30. Brasil. Instituto do Patrimônio Histórico e Artístico Nacional. Processo no 01450.016835/2009-92, que trata do pedido de registro da produção de doces tradicionais pelotenses. Ofício no 0256/2010, Nota Técnica no 21/2010, da técnica Diana Dianovsky. Inventário Nacional de Referências Culturais da Produção de Doces Tradicionais Pelotenses, coordenado pela antropóloga Flávia Rieth, do Laboratório de Ensino e Pesquisa em Antropologia e Arqueologia da Universidade Federal de Pelotas e Parecer dos técnicos Beatriz Muniz Freire e Marcos Vinicius Benedeti. Brasília: IPHAN; 2009/2010.

31. Pinto MDN. Mandioca e farinha: identidade cultural e patrimônio nacional. In: Brasil. Ministério do Meio Ambiente. Agrobiodiversidade e diversidade cultural. Brasília: MMA; 2006. p. 25-27. (Série Biodiversidade, 20).

32. Pinto MDN. Sabores e saberes da casa de Mani. Revista do Patrimônio Histórico e Artístico Nacional 2005; (32):281-301.

33. Robert P, Velthem LV. L'heure du tacacá: consommation et valorisation d'aliments traditionnels amazoniens en zone urbaine (Brésil). Anthropology of Food [Internet] 2008; (S4): 12 p. [acesso em: 10 dez. 2014]. Disponível em: http://aof.revues.org/3533

34. Brasil. Instituto do Patrimônio Histórico e Artístico Nacional. Ofício das Baianas de Acarajé. Brasília: IPHAN; 2007. (Coleção Dossiê dos Bens Culturais Registrados, 6).

35. Santos VJR. O Acarajé nas políticas públicas: reconhecimento do ofício das baianas de acarajé como patrimônio cultural do Brasil. In: I Seminário sobre Alimentos e Manifestações Culturais Tradicionais; 21-23 maio 2012; São Cristóvão, (SE).

36. Bitter D, Bitar NP. Comida, trabalho e patrimônio: notas sobre o ofício das baianas de acarajé e das tacacazeiras. Horiz. Antropol. 2012; 18(38):213-36.

37. Brasil. Instituto do Patrimônio Histórico e Artístico Nacional. Processo no 01450.014958/2010/22, que trata do registro do ofício das tacacazeiras. Dossiê e Nota Técnica no 22/2010, da técnica Luciana Borges Luz. Brasília: IPHAN; 2010.

Recebido: $15 / 4 / 2015$

Revisado: $10 / 6 / 2015$

Aprovado: 07/7/2015 